\title{
Primary orbital extraskeletal osteosarcoma and review of literature
}

Jingwen Hui ${ }^{1,2,3,4}$, Yun Zhao ${ }^{1,2,3,4}$, Lei Zhang ${ }^{1,2,3,4}$, Jinyong Lin ${ }^{1,2,3,4}$ and Hong Zhao ${ }^{1,2,3,4^{*}}$ (D)

\begin{abstract}
Background: Extraskeletal osteosarcoma is a malignant tumour composed of an osteoid and/or cartilaginous matrix; it arises in soft tissues without connection to the skeleton, and to our knowledge, this type of tumour is extremely rare.

Case presentation: The present study reports a 57-year-old man with primary orbital extraskeletal osteosarcoma who presented with a history of painful swelling in the left orbit that had occurred for 11 months. Imaging of the orbit showed an atypical, well-defined heterogeneous mass attached to the posterior globe of the left orbit. The patient underwent an anterior orbitotomy and complete excision of the tumour. The mass was originated from neither the globe nor the bony orbital wall but from the soft tissue. Histopathology demonstrated an extraskeletal osteosarcoma. After 13 months of follow-up, there was apparent recurrence of the tumour. The medical history showed no complaints of previous trauma or radiotherapy.

Conclusions: ESOS is a highly malignant tumour. Immunosuppression, trauma and adjuvant radiotherapy are possible predisposing factors in the development of this tumour. Prompt recognition and thorough treatment are essential for preventing orbital lesions and presence of metastasis from other organs.
\end{abstract}

Keywords: Orbit, Osteosarcoma, Extraskeletal osteosarcoma

\section{Background}

Extraskeletal osteosarcoma (ESOS) is an extremely rare tumour that is not usually located in the orbit. It is defined as a malignant mesenchymal neoplasm that produces an osteoid and/or cartilaginous matrix and arises in soft tissues without connection to the skeleton. It is rare and comprises fewer than $5 \%$ of all osteosarcomas. Only 4 previous cases of orbital ESOS have been reported. Extraskeletal osteosarcoma primarily affects patients over the age of 50 years and has a poor prognosis. Our patient is the oldest and the fourth case ever detected with primary orbital ESOS without a history of previous radiotherapy or trauma. In this report, we

\footnotetext{
* Correspondence: zhaohongeye@163.com

'Tianjin Eye Hospital, Tianjin Eye Institute, NO.4 Gansu Road, Heping District, Tianjin 300020, China

${ }^{2}$ Tianjin Key Lab of Ophthalmology and Visual Science, Tianjin, China

Full list of author information is available at the end of the article
}

describe the clinical, radiologic, and pathologic records of a rare case of primary orbital extraskeletal osteosarcoma.

\section{Case presentation}

A 57-year-old male presented with painful swelling in the left orbit that had occurred for 11 months. The medical history showed no chronic systemic disease, sinus infection, mucocele, previous trauma, previous eye surgery or irradiation.

We performed a complete ophthalmic examination. Best-corrected visual acuity was 20/25 OD and 20/70 OS. Examination of the left eye revealed a $3 \mathrm{~mm}$ proptosis and maximal restriction of extraocular movements in all gazes. Funduscopic examination revealed diffuse choroidal fold in the left eye (Fig. 1). Right eye examination was unremarkable. 


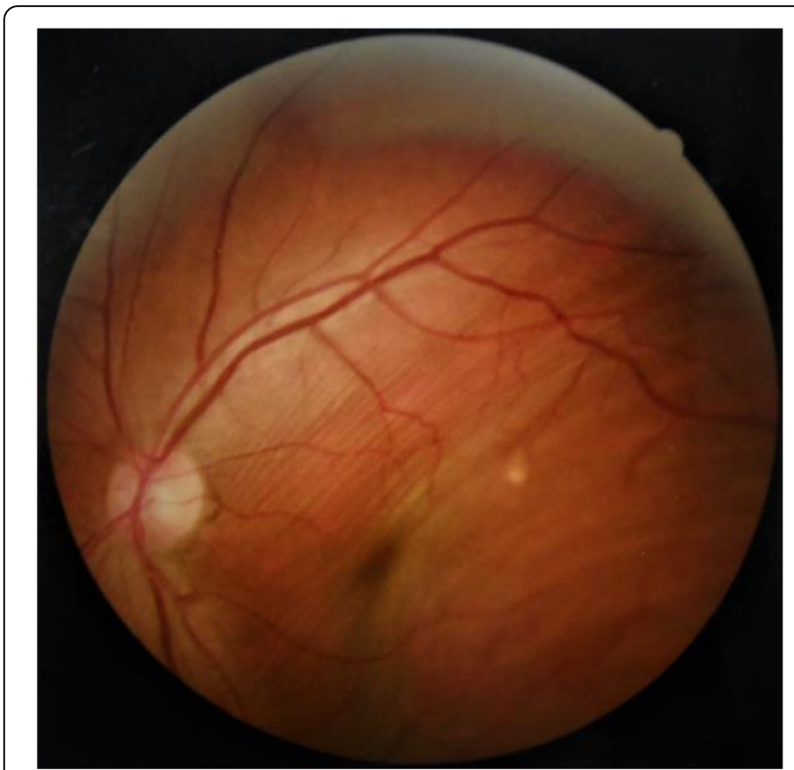

Fig. 1 Diffuse choroidal fold was shown in left eye in the fundus photography

Computed tomography (CT) of the orbit revealed an atypical, well-circumscribed homogeneous calcified mass attached to the posterior globe of the left orbit (Fig. 2 ab). Orbital magnetic resonance imaging showed a mixed heterogeneous mass with hypo and hyperintense regions (Fig. 2 c-d). The mass was measured $1.77 \times 1.41 \times 2.42$ $\mathrm{cm}$ in size in the left orbit and was located within the muscle cone.

The patient underwent an anterior inferior orbitotomy, and complete excision of the mass. Intraoperatively, the tumour was attached to the sclera but not attached to any of the orbital structures. The tumour wraps the inferior oblique, lateral rectus, and part of the inferior rectus muscle. The sclera was intact and the surface was slightly rough. The tumour caused indentation of the globe but did not enter the globe. Gross examination revealed an atypical, wellencapsulated grey-brown bony mass with several small, separate, nodules. The cut surface was greywhite, lobulated and bony hard in consistency. Microscopic examination revealed malignant spindle cells with abundant neoplastic bone and cartilage formation (Fig. 3 a-b). Immunohistochemical examination was positive for vimentin and S-100(Fig. $3 \mathrm{c}$-d) and negative for desmin, CD99 and EMA. The patient underwent PET-CT examination before surgery and found no distant metastases from this lesion or for occult primary lesions that may have led to a metastatic lesion within the orbit.

The 13-month follow-up included CT scans every 3 months and subsequently every 6 months. The patient encountered recurrence of the tumour. A complete ophthalmic examination was performed. Visual acuity was 20/25 OD and 20/200 OS. Examination of the left eye revealed a $1 \mathrm{~mm}$ proptosis and restriction of extraocular movements in all gazes. Funduscopic examination revealed diffuse choroidal fold in the left eye. Right eye examination was unremarkable. The latest orbital CT (Fig. 4) showed an irregular shape of the soft tissue in the muscle cone of the left eyeball. The lesions showed irregular massive calcification, and the tumour was close to the posterior pole, which was compressed and deformed. The boundary between the mass and the medial rectus muscle and the inferior rectus muscle was unclear, which revealed that the muscle was probably attached. The CT value of the soft tissue lesions was $52 \pm 7.62 \mathrm{HU}$, while that of calcification was $319.09 \pm 84.31 \mathrm{HU}$. Considering the patient's medical history, due to the invasive nature of the tumour, the patient then underwent orbital exenteration of the left orbit. The tumour was confirmed after surgery. Pathological examination showed a recurrence of extraskeletal osteosarcoma outside the orbit, and the lesion was extensively invaded by the soft tissue and the posterior sclera.

The pathological diagnosis was recurrent orbital extraskeletal osteosarcoma.

\section{Discussion and conclusion}

ESOS is a rare malignant mesenchymal neoplasm, which located in soft tissue without connection to the skeleton. Only 4 cases of ESOS in the orbital region have been reported in the literature (Table 1) [1-4]. Since it was first described by Wilson [5] in 1941, only a limited range of publications about this rare neoplasm have been published. ESOS is a relatively unusual soft tissue tumour, with an incidence of $1-2 \%$ of all soft tissue sarcomas and $4 \%$ of all osteosarcomas [6]. Osteosarcoma of the bone occurs mainly around the age of 20, whereas ESOS has been reported in adults with an average age of 52 [7] .The most typical sites of ESOS are the lower extremities, girdle, the thigh muscle, and retroperitoneum [8], while in principle ESOS can arise in any part of the body and rarely occurs in the orbit.

Research focusing on the clinical behaviour of ESOS is limited. Localized pain, swelling and oedema are the most common presenting symptoms [9]. The duration of symptoms varies from weeks to years and most series report an average duration of $4 \pm 6$ months $[9,10]$. The diagnosis tends to be delayed because symptoms are often absent or vague according to documents [11]. ESOS can be asymptomatic or 



Fig. 2 a, The transverse computed tomography revealed an atypical, well-circumscribed homogeneous calcified mass attached the posterior globe in the left orbit. b, The coronal computed tomography showed a calcified mass neither origined from the globe nor the bony orbital wall. c, The transverse T1Wl section showed the heterogeneous lesion. The lesion was approximately $17.7 \times 14.1 \times 24.2 \mathrm{~mm}$ in the orbit. $\mathbf{d}$, The coronal $\mathrm{T} 2 \mathrm{Wl}$ section showed the heterogeneous lesion presents hypointense in the left orbit

symptomatic. The presenting symptoms are typically due to tumour enlargement and pain. As with other neoplasms, the aetiology of ESOS is difficult to determine. Radiation and trauma are regarded as major incriminating factors. However, there was no evidence of previous trauma or irradiation in our case.

In our case, the differential diagnosis should be as follows:(1) choroidal osteoma,(2) mesenchymal chondrosarcoma. Choroidal osteoma has not been suggested because the imaging studies showed only the limited lesions of the choroid with the presence of cancellous bone and vascular channels within the choroid, and this type of tumour commonly occurs in healthy females in their 2nd or 3rd decades of life. Without the component of cartilage and accordant pathological examination, the diagnosis of mesenchymal chondrosarcoma was not supported.

The most common genetic changes associated with osteosarcoma are the alterations of the p53 tumour suppressor gene and loss of the retinoblastoma gene RB1on the chromosome [12]. In the present case, alterations of p53 and expression levels of RB1 were not tested. The aetiology of sporadic cases is not clear, appearing to be associated with the cumulative effect of susceptibility loci on other chromosomes controlling the mechanisms of cell proliferation, differentiation, and maturation.

The common metastatic sites of involvement are the lungs, followed by the lymph nodes, kidneys, thyroid, liver, spleen and other viscera [13]. The treatment of ESOS includes radical surgery and polychemotherapy [14]. Treatment of ESOS is primarily surgical with wide excision or radical resection. Radical resection appears to be the best therapeutic option for local control but has no effect on distant metastasis [15], which also does not seem to improve survival in patients treated with wide excision. Adjuvant chemotherapy or preoperative radiation therapy 


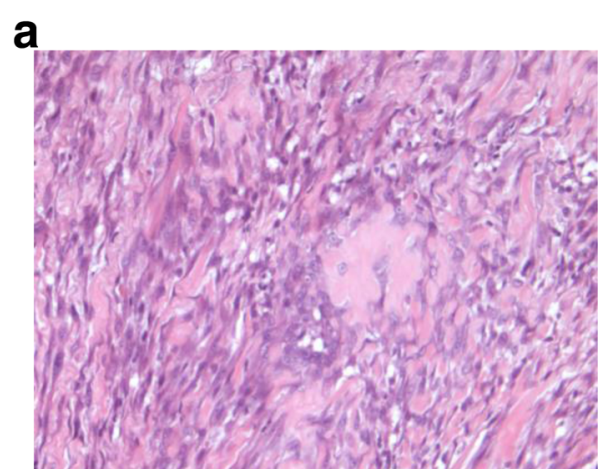

c

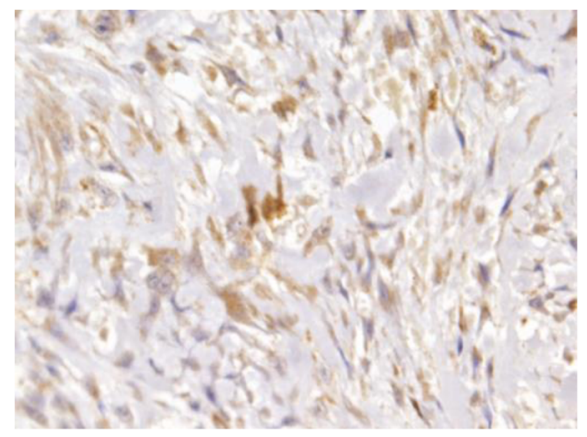

b

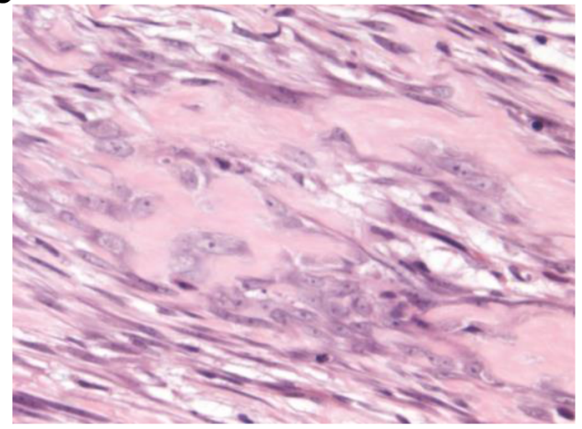

d

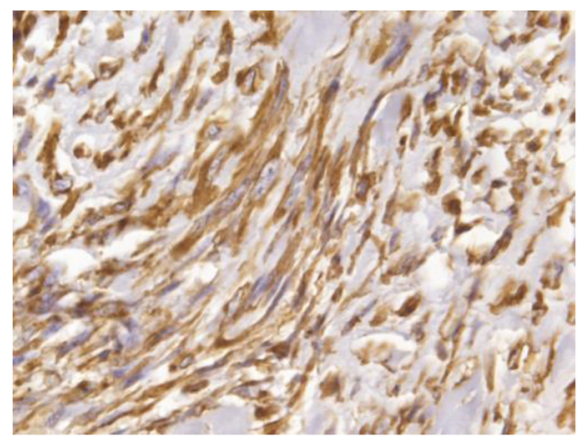

Fig. 3 a Hematoxylin-eosin staining with low-power view showing bizarre tumor cells and osteoid with atypical mitotic figures. (hematoxylineosin, original magnification $\times 200$ ). $\mathbf{b}$ High-power view of the cellular area showing malignant spindle cells with abundant neoplastic bone and cartilage formation (hematoxylin-eosin, original magnification $\times$ 400). c-d Immunohistochemical examination showing positivity of tumor cells to S-100(c) and Vimentin (d) (original magnification $\times 400$ )

appears to be useful. Radiotherapy can be used in patients with large lesions or marginal excision, while chemotherapy is not commonly used except for palliation. Various chemotherapy protocols have been used in advanced and metastatic disease and the outcome was uniformly poor. Although some cases have

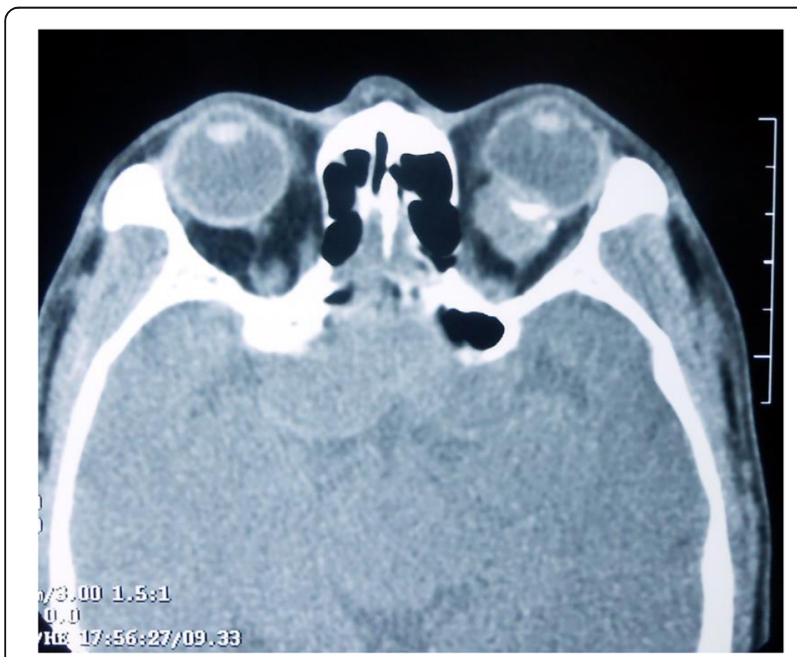

Fig. 4 Preoperative $\mathrm{CT}$ in the recurrence been reported to be treated by radiotherapy or systemic chemotherapy, the treatments are not well established.

In summary, ESOS is a highly malignant tumour. If a patient shows the orbital signs of suspicious of ESOS, we recommend that a diagnosis should be promptly performed, and appropriate surgery in terms of excision is a prerequisite. Patients should be carefully monitored with very close follow up and should be warned about symptoms and signs of

Table 1 Cases of extraskeletal osteosarcoma in the orbital region reported in the literature

\begin{tabular}{llllll}
\hline $\begin{array}{l}\text { Ref. } \\
\text { No. }\end{array}$ & Author (yr) & $\begin{array}{l}\text { Age } \\
\text { (yrs)/ } \\
\text { Sex }\end{array}$ & $\begin{array}{l}\text { Primary } \\
\text { malignancies }\end{array}$ & $\begin{array}{l}\text { Prior } \\
\text { history } \\
\text { irradiation }\end{array}$ & Outcome \\
\hline$[1]$ & $\begin{array}{l}\text { Kauffman and } \\
\text { Stout (1963) }\end{array}$ & $11 / \mathrm{M}$ & Retinoblastoma & Present & NR \\
[2] & $\begin{array}{l}\text { Jacob et al. } \\
\text { (1998) }\end{array}$ & 22/M & Absent & Absent & NED \\
[3] & Fan et al. (2011) & $78 / M$ & $\begin{array}{l}\text { Basal cell } \\
\text { carcinoma }\end{array}$ & Present & NED \\
[4] & $\begin{array}{l}\text { De Maeyer et al. 32/M } \\
\text { Absent }\end{array}$ & Absent & NED \\
\hline
\end{tabular}

$M$ male, NED no evidence of disease, NR not reported 
recurrence after surgery, which can rapidly progress and cause severe visual impairment. Prompt recognition and thorough treatment are essential for preventing orbital lesions and presence of metastasis from other organs.

\section{Abbreviations}

ESOS: Extraskeletal osteosarcoma; CT: Computed Tomography;

T1WI: T1weighted image; T2WI: T2weighted image; EMA: Human Epithelial membrane antigen; HU: Hounsfield unit

\section{Acknowledgements}

The authors thanked the patient who generously agreed to participate in this report. The authors also thanked Dr. Zhao for interaction with the patient as well as his excellent assistance in the draft of the manuscript.

\section{Authors' contributions}

HJW drafted the manuscript, collected the data and reviewed the literature. $Z Y$ interpreted the data, reviewed the literature and helped to drafted the manuscript. LZ and JYL were involved in the design of the study and coordination. ZH performed surgery, made diagnosis, and critically reviewed the manuscript. All authors read and approved the final manuscript.

\section{Funding}

This report was supported by YKYB1914 of Science and Technology Foundation. Tianjin Eye Hospital plays the role of founder.

\section{Availability of data and materials}

All datasets used and/or analysed in the current study are available from the corresponding author upon reasonable request.

\section{Ethics approval and consent to participate}

This study was conducted in accordance with the tenets of the Declaration of Helsinki and was approved by Tianjin Eye Hospital Foundation Institutional Review Board (TJYYL-2019-13). All authors had permission to access patient records. We confirmed that all written consent was obtained from the participant.

\section{Consent for publication}

Written informed consent was obtained from the patient for publication of this case report and any accompanying images. A copy of the written consent is available for review by the Editor of this journal.

\section{Competing interests}

The authors report no conflicts of interest. The authors alone are responsible for the content and the writing of the article.

\section{Author details}

'Tianjin Eye Hospital, Tianjin Eye Institute, NO.4 Gansu Road, Heping District,

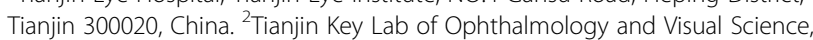
Tianjin, China. ${ }^{3}$ Clinical College of Ophthalmology Tianjin Medical University,

Tianjin, China. ${ }^{4}$ Nankai University Eye Hospital, Tianjin, China.

Received: 31 January 2020 Accepted: 8 October 2020

Published online: 22 October 2020

\section{References}

1. Kauffman SL, Stout AP. Extraskeletal osteogenic sarcomas and chondrosarcomas in children. Cancer. 1963;16:432-9.

2. Jacob R, Abraham E, Jyothirmayi R, Nair MK. Extraskeletal osteosarcoma of the orbit. Sarcoma. 1998;2:121-4.

3. Fan JC, Lamont DL, Greenbaum AR, Ng SG. Primary orbital extraskeletal osteosarcoma. Orbit. 2011;30:297.299.

4. De Maeyer VMDS, Kestelyn PAFA, Shah AD, Van Den Broecke CM, Denys HGN, Decock CE. Extraskeletal osteosarcoma of the orbit: a clinicopathologic case report and review of literature. Indian J Ophthalmol. 2016;64:687.689.

5. Wilson H. Extraskeletal ossifying tumors. Ann Surg. 1941;113:95-112.

6. Lauren AR, Ivan C, Miriam AB, et al. Clinical, radiological, and pathological features of extraskeletal osteosarcoma.Skeletal Radiol. 2018;47(9):1213-20.
7. Allan CJ, Soule EH. Osteogenic sarcoma of the somatic soft tissue:a clinicopathologic study of 26 cases and review of the literature. Cancer. 1972;27:1121-33.

8. Marilyn $\mathrm{H}$, Abha G, Peter WC, et al. The role of chemotherapy and radiotherapy in localized extraskeletal osteosarcoma. Eur J Cancer. 2020;125: 130-41.

9. Rao U, Cheng A, Didolkar MS. Extraosseous osteogenic sarcomaClinicopathological study of eight cases and review of literature. Cancer. 1978:41:1488-96.

10. Sordillo P, Hajdu SI, Magill GB, et al. Extra skeletal osteosarcoma:s a review of 48 cases. Cancer. 1983:51:727-34.

11. Tao $\mathrm{S}$, Tian G, Ge M, et al. Primary extraskeletal osteosarcoma of omentum majus. World J Surg Oncol. 2011;9:25

12. De Maeyer VMDS, Kestelyn PAFA, Shah AD, Van Den Broecke CM, Denys HGN, Decock CE. Extraskeletal osteosarcoma of the orbit: aclinicopathologic case report and review of literature. Indian J Ophthalmol. 2016;64:687-9.

13. Allan CJ, Soule EH. Osteogenic sarcoma of the somatic soft tissues. Clinicopathologic study of 26 cases and review of literature. Cancer. 1971; 27(5):1121-33.

14. Goldstein-Jackson SY, Delling G, Berdel WE, Exner GU, Jundt G, Machatschek $\mathrm{JN}$, et al. Extraskeletal osteosarcoma has a favourable prognosis when treated like conventional osteosarcoma. J Cancer Res Clin Oncol. 2005;131: 520-6.

15. Schneider JR, Sener SF, Barrera E. Combined replacement of infrarenal aorta and inferior vena cava after en bloc resection of retroperitoneal extraosseous osteosarcoma. J Vasc Surg. 2008;48(2):478-9.

\section{Publisher's Note}

Springer Nature remains neutral with regard to jurisdictional claims in published maps and institutional affiliations.

\section{Ready to submit your research? Choose BMC and benefit from:}

- fast, convenient online submission

- thorough peer review by experienced researchers in your field

- rapid publication on acceptance

- support for research data, including large and complex data types

- gold Open Access which fosters wider collaboration and increased citations

- maximum visibility for your research: over $100 \mathrm{M}$ website views per year

At BMC, research is always in progress.

Learn more biomedcentral.com/submissions 